\title{
PERANCANGAN ULANG TATA LETAK PABRIK MENGGUNAKAN METODE ALGORITMA COMPUTERIZED RELATIVE ALLOCATION OF FACILITIES TECHNIQUES (CRAFT)
}

\author{
Supriyadi*, Dedi Setiawan, Dadi Cahyadi \\ Program Studi Teknik Industri, Fakultas Teknik, Universitas Serang Raya \\ Email: supriyadi@unsera.ac.id; setiawankecu@gmail.com; dadicahyadi@gmail.com
}

$\begin{array}{ll}\text { Artikel masuk : 02-12-2019 } & \begin{array}{c}\text { Artikel direvisi : 27-12-2019 } \\ \\ \end{array} \text { *Penulis Korespondensi }\end{array}$

\begin{abstract}
Abstrak - Biaya material handling merupakan salah satu penyumbang biaya yang besar dalam proses produksi perusahaan. Seperti pada sebuah perusahaan manufaktur di Banten, biaya material handling pada tahun tidak sesuai dengan target yang telah ditetapkan perusahaan. Penelitian ini bertujuan memperbaiki aliran proses yang berhubungan dengan material handling. Penelitian ini menggunakan metode algoritma Computerized Relative Allocation of Facilities Techniques (CRAFT) yang mempunyai konsep melakukan pertukaran antar departemen berdasarkan biaya material handling. Data yang digunakan untuk penelitian ini antara lain biaya material handling, tata letak awal, frekuensi perpindahan barang, dan jumlah departemen yang tetap. Berdasarkan pengolahan data yang telah dilakukan perubahan tata letak yang dilakukan mampu mengurangi biaya material handling sebesar Rp. 298,320.00 dengan selisih jarak sebesar 26.400 meter. Pengaturan tata letak dengan memperhatikan biaya material handling mampu mengurangi total biaya proses produksi dan mengefisienkan aliran proses produksi.
\end{abstract}

Kata kunci: Algoritma CRAFT; Material Handling; Tata Letak

\begin{abstract}
Material handling costs are one of the significant cost contributors in the process of a company's production. As in a manufacturing company in Banten, the cost of material handling in the year was not by the target set by the company. This study aims to improve the flow of processes related to material handling. This study uses the Computerized Relative Allocation of Facilities Techniques (CRAFT) algorithm, which has the concept of exchanging between departments based on material handling costs. The data used for this study include the cost of material handling, initial layout, frequency of movement of goods, and a fixed number of departments. Based on the data processing that has been done the layout changes made can reduce material handling costs by Rp. 298,320.00 with a difference of 26,400 meters. Layout arrangements that pay attention to material handling costs can reduce the total cost of the production process and streamline the production process flow.
\end{abstract}

Keywords: CRAFT Algorithm; Material Handling; Layout

\section{PENDAHULUAN}

Tata letak fasilitas merupakan desain pengaturan fasilitas fisik dengan memperhatikan sumber daya dalam menghasilkan suatu produk (Deshpande, Patil, Baviskar, \& Gandhi, 2016). Perencanaan fasilitas mempunyai manfaat yang penting dalam industri manufaktur mencapai efektivitas aliran proses. Aliran proses yang baik mampu mengurangi total biaya aktivitas
(Deshpande \& Chopade, 2005) dan menyediakan ruang yang optimal dalam mencapai efisiensi dan efektifitas organisasi perusahaan (Kartika, 2014). Aktifitas produksi secara normal berlangsung dalam waktu yang panjang, sehingga pengaturan fasilitas bisa menyebabkan kerugian.

Pemilihan dan penempatan fasilitas memerlukan perencanaan yang baik karena akan menentukan hubungan fisik dari aktifitas produksi 
yang berlangsung, terutama berhubungan dengan sistem pemindahan bahan material (material handling). Material handling berhubungan dengan pemindahan barang dari satu fasilitas dengan fasilitas produksi yang lain atau suatu departemen dengan departemen lain. Kenyataannya material handling tidak hanya sekedar memindahkan barang saja. Pada beberapa perusahaan, material handling bisa mencapai setengah dari total biaya produksi yang dikeluarkan (Green, Lee, \& Kozman, 2010) atau menyumbang 30-75\% dari total biaya produk (Sujono \& Lashkari, 2007). Hal ini terjadi karena aliran, pergerakan, dan penyimpanan dalam proses produksi suatu produk memerlukan banyak sumber daya, baik sumber daya manusia maupun peralatan.

Penanganan material diperlukan untuk efektivitas penyelesaian proses produksi dan mempunyai pengaruh yang nyata dalam memenuhi tujuan manajerial perusahaan (Stephens \& Meyers, 2013). Sistem material handling yang baik mampu meningkatkan kinerja perusahaan terutama mengurangi Work In Process (WIP) (Mohamed, Rashid, Rose, \& Ting, 2015). Oleh karena itu, penting untuk menentukan peralatan penanganan material yang sesuai dan tugas operasi penanganan material untuk masingmasing peralatan.

Algoritma Computerized Relative Allocation of Facilities Technique (CRAFT) merupakan salah satu metode yang bisa digunakan untuk pengaturan tata letak fasilitas. Algoritma CRAFT merupakan algoritma heuristik yang mengambil matriks beban aliran antar departemen dan biaya transaksi dengan representasi tata letak blok sebagai input (Buffa, 1964). Pada perkembangannya, metode ini dikembangkan untuk prioritas biaya penanganan material (Esmaeili Aliabadi \& Pourghannad, 2012). Beberapa penelitian menunjukkan algoritma CRAFT mampu memperbaiki tata letak berdasarkan proses (Lekan, Kayode, \& Abdulrazaq Morenikeji, 2017; Sembiring et al., 2019; VirendraPatil \& Sagare, 2017) dan keragaman produk (Hedau \& Sharma, 2016).

Permasalahan besarnya biaya material handling juga dialami sebuah perusahaan manufaktur di daerah Banten. Pada tahun 2016 pengeluaran cost material handling perusahaan tidak sebanding dengan target yang telah ditetapkan perusahaan. Penelitian ini bertujuan untuk mengatur ulang dan memperbaiki aliran proses produksi yang berhubungan dengan material handling.

\section{METODE PENELITIAN}

Penelitian dilakukan pada perusahaan yang memproduksi nikel pig iron dari ferro nickel ore deposit di daerah Cilegon, Banten. Penelitian dilakukan tanggal 04 Agustus 2016 s.d 03 September 2016. Analisis data menggunakan algoritma CRAFT untuk memperbaiki aliran proses kerja berdasarkan material handling.

Pemilihan metode CRAFT karena metode ini mempunyai kelebihan dalam menetapkan lokasi khusus dengan waktu komputasi yang pendek dan sederhana (Ristyanadi \& Orchidiawati, 2019), serta memiliki arti matematis untuk meminimalkan biaya material handling dan jarak antar fasilitas (Pailin, 2013). Input yang diperlukan dalam perencanaan layout dalam algoritma CRAFT antara lain sistem aliran barang, sistem material handling, urutan proses, luas area kerja, urutan proses produksi maupun data-data lain yang berkaitan dengan layout (Apple, 1990).

Algoritma CRAFT membuat perancangan yang optimum dengan melakukan perbaikan tata letak secara bertahap. Evaluasi tata letak CRAFT dengan cara melakukan pertukaran lokasi antar departemen sampai mendapatkan biaya material handling yang minimal. Perubahan lokasi departemen dengan memperhatikan biaya material handling, tata letak awal, frekuensi perpindahan barang, dan jumlah departemen yang tetap (White, Francis, Francis, \& McGinnis, 1992)

\section{HASIL DAN PEMBAHASAN}

Proses awal peleburan baja berada pada proses sintering. Prinsip sintering melibatkan pemanasan bijih besi bersama dengan fluks dan coke untuk menghasilkan massa semi-cair yang mengeras menjadi potongan-potongan berpori dari sinter dengan ukuran dan kekuatan karakteristik yang diperlukan untuk memberi masukan ke dalam blast furnace. Hal ini pada dasarnya adalah proses aglomerasi yang dicapai melalui pembakaran. Produk dari proses sintering disebut sinter dan memiliki karakteristik kualitas.

Berdasarkan layout yang diperoleh dari perusahaan (Gambar 1), penelitian ini tidak membahas semua aliran proses tetapi hanya dari raw material nikel sampai raw material sinter. Pemilihan proses ini disebabkan perpindahan material ini adalah terjadi banyak kendala yang berhubungan dengan perpindahan material dan merupakan proses utama dalam proses peleburan baja. Perbandingan waktu di lantai produksi material handling dan lantai produksi peleburan baja adalah $1: 2$, dalam artian dalam 2 hari bekerja di lantai produksi material handling sintering dapat diselesaikan dalam satu hari proses peleburan baja di bagian Blast Furnace. Perpindahan material menggunakan Loader yang mempunyai kapasitas 10 Ton dan dump truck dengan kapasitas 40 ton dalam sekali angkut. Adapun ukuran untuk empat departemen yang menjadi objek penelitian dapat dilihat pada tabel 1 . 
1000 Meter

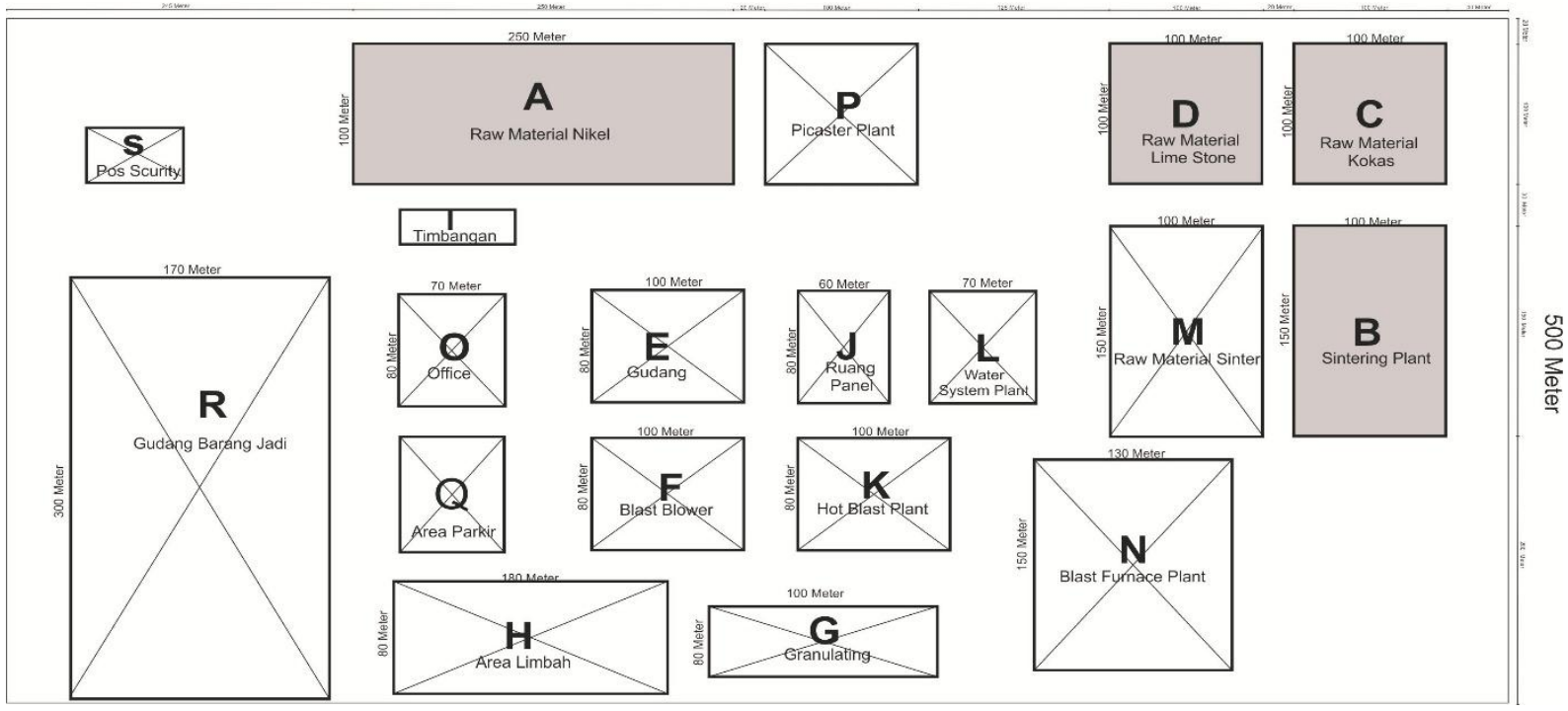

Gambar 1 Tata Letak Pabrik Secara lengkap

Tabel 1. Tabel luas gedung

\begin{tabular}{clcccc}
\hline No & Nama Gedung & $\begin{array}{c}\text { Kode } \\
\text { Gedung }\end{array}$ & $\begin{array}{c}\text { Panjang } \\
\text { Bangunan } \\
\text { (meter) }\end{array}$ & $\begin{array}{c}\text { Lebar } \\
\text { Bangunan } \\
\text { (meter) }\end{array}$ & $\begin{array}{c}\text { Luas } \\
\text { bangunan } \\
\text { (meter) }\end{array}$ \\
\hline 1 & Raw Material Nikel & A & 250 & 100 & 25000 \\
2 & Raw Material Limestone & C & 100 & 100 & 10000 \\
3 & Raw Material Kokas & D & 100 & 100 & 10000 \\
4 & Sintering Plant & B & 100 & 150 & 15000 \\
\hline
\end{tabular}

Tabel 2. Jarak Material Handling

\begin{tabular}{cccccc}
\hline No & $\begin{array}{c}\text { Hubungan aliran } \\
\text { pemindahan } \\
\text { bahan }\end{array}$ & $\begin{array}{c}\text { Jarak } \\
\text { perpindahan } \\
\text { bahan (M) }\end{array}$ & $\begin{array}{c}\text { Frekuensi } \\
\text { Perpindahan }\end{array}$ & $\begin{array}{c}\text { Jarak } \\
\text { Tempuh (M) }\end{array}$ & $\begin{array}{c}\text { Ongkos Material } \\
\text { Handling (OMH) }\end{array}$ \\
\hline 1 & A - B & 710 & 72 & 51120 & $\mathrm{Rp} 577,656.00$ \\
2 & $\mathrm{C}-\mathrm{B}$ & 320 & 48 & 15360 & $\mathrm{Rp} 173,568.00$ \\
3 & $\mathrm{D}-\mathrm{B}$ & 160 & 24 & 3840 & $\mathrm{Rp} 43,392.00$ \\
\hline & Total & & 70320 & $\mathrm{Rp} 794,616.00$ \\
\hline
\end{tabular}

Ongkos Material Handling (OMH) didapatkan dari biaya pemakaian bahan bakar Dump Truck, setiap menempuh jarak 500 meter, membutuhkan biaya bahan bakar sebanyak 1 liter dengan nominal harga Rp. 5.650/lt (Tabel 2). Sedangkan biaya material handling untuk pekerjanya tidak diperhitungkan dikarenakan karyawan mendapatkan gaji setiap bulannya. Perhitungan jarak material handling berdasarkan sumbu tiap departemen dengan titik pusat (tabel 3). Berdasarkan sumbu tersebut, diperoleh jarak A ke
B sejauh 710 meter, $C$ ke B sejauh 160 meter dan 320 meter jarak antara D ke B.

Tabel 3. Jarak Material Handling dari titik pusat

\begin{tabular}{crc}
\hline $\begin{array}{c}\text { Kode } \\
\text { Area }\end{array}$ & $\begin{array}{c}\text { Sumbu X } \\
\text { (meter) }\end{array}$ & $\begin{array}{c}\text { Sumbu Y } \\
\text { (meter) }\end{array}$ \\
\hline A & 0 & 160 \\
C & 160 & 160 \\
D & 550 & 160 \\
B & 0 & 0 \\
\hline
\end{tabular}


Asumsi dari metode algoritma Craft adalah dengan melakukan pertukaran antar bangunan yang dapat dipertukarkan, Dari data layout tata letak awal, letak Raw Material Nikel cukup jauh jaraknya dengan pusat produksi sintering. Perlu alternatif perubahan fungsi gedung sampai mendapatkan biaya material handling yang optimum. Dari beberapa percobaan yang dilakukan diperoleh rancangan baru dengan mendekatkan posisi raw material nikel dekat dengan titik pusat (Gambar 2).

Perubahan tata letak ini berdampak pada perubahan biaya material handling yang berhubungan dengan biaya bahan bakar kendaraan sebesar Rp . 496,296.00 (Tabel 4). Biaya ini lebih kecil jika dibandingkan dengan biaya awal sebesar Rp 794,616.00. Perpindahan lokasi ini juga berdampak pada jarak antar departemen yaitu jarak antara area A ke B sebesar 160 meter, C ke
B sejauh 160 meter dan 710 meter jarak antara D ke B.

Perubahan area berdampak pada area departemen mengurangi total jarak layout awal total jarak perpindahan material dari 70320 meter menjadi 43920 meter, maka selisih jarak perpindahan material adalah 26400 meter. Selisih jarak ini berpengaruh terhadap biaya material handling dengan selisih sebesar Rp. 298,320.00 atau mampu menghemat biaya material handling sebesar $37,5 \%$. Penghematan ini sesuai dengan penelitian yang sejenis, dimana penggunaan algoritma CRAFT mampu menurunkan biaya material handling di atas 30\% (Altinkilinc, 2004; Prasad, Rajyalakshmi, \& Reddy, 2014). Pengurangan ini membuktikan bahwa CRAFT sangat efektif memperbaiki tata letak fasilitas yang berhubungan dengan material handling (Leung, Quintana, \& Chen, 2008)

\section{Meter}

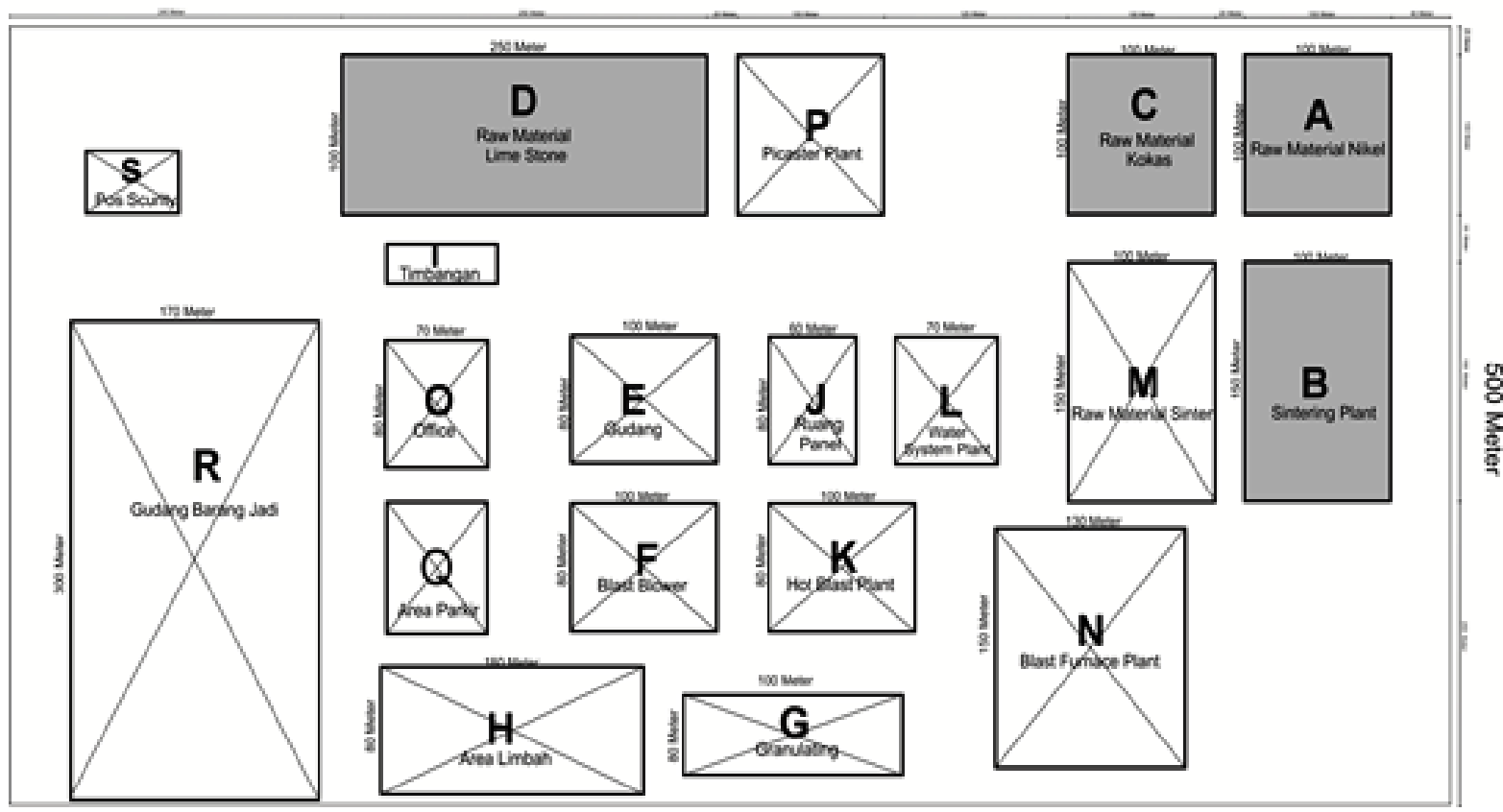

Gambar 2. Layout usulan

Tabel 4. Analisa Total Jarak Material Handling

\begin{tabular}{|c|c|c|c|c|c|}
\hline No & $\begin{array}{l}\text { Hubungan aliran } \\
\text { pemindahan bahan }\end{array}$ & $\begin{array}{c}\text { Jarak } \\
\text { perpindahan } \\
\text { bahan (M) }\end{array}$ & $\begin{array}{c}\text { Frekuensi } \\
\text { Perpindahan }\end{array}$ & $\begin{array}{l}\text { Jarak Tempuh } \\
\text { (M) }\end{array}$ & $\begin{array}{c}\text { Ongkos Material } \\
\text { Handling }(\mathrm{OMH}) \\
\mathrm{OMH}\end{array}$ \\
\hline 1 & $A-B$ & 160 & 72 & 11520 & Rp. $130,176.00$ \\
\hline 2 & $C-B$ & 320 & 48 & 15360 & Rp. $173,568.00$ \\
\hline \multirow[t]{2}{*}{3} & $D-B$ & 710 & 24 & 17040 & Rp. $192,552.00$ \\
\hline & & & Total & 43920 & Rp. $496,296.00$ \\
\hline
\end{tabular}




\section{KESIMPULAN}

Dari hasil analisa yang telah dilakukan di atas, maka dapat disimpulkan bahwa algoritma Craft mampu menghasilkan solusi yang optimal dengan hanya mempertukarkan beberapa fugsi fasilitas. Perubahan desain mampu memperkecil jarak material handling sebesar 26400 meter dengan pengurangan biaya sebesar Rp. 298,320.00 (37,5\%). Algoritma CRAFT tidak menjamin tata letak yang diperoleh lebih murah karena semua kemungkinan pertukaran tidak dipertimbangkan. Penelitian ini dapat dilanjutkan pada penggunaan algoritma lain yang memperhatikan batasan-batasan selain biaya material handling.

\section{DAFTAR PUSTAKA}

Altinkilinc, M. (2004). Simulation-based layout planning of a production plant. In Proceedings of the 2004 Winter Simulation Conference, 2004. (Vol. 2, pp. 1079-1084). IEEE.

Apple, J. M. (1990). Tata letak dan pemindahan bahan. Bandung: ITB Press.

Buffa, E. S. (1964). Allocating facilities with CRAFT. Harvard Business Review, 42(2), 136-159.

Deshpande, V. A., \& Chopade, I. K. (2005). Facility Layout Design by CRAFT Technique.

Proceedings COMPUTIME: September, 16, 17.

Deshpande, V., Patil, N. D., Baviskar, V., \& Gandhi, J. (2016). Plant layout optimization using CRAFT and ALDEP methodology. Productivity Journal by National Productivity Council, 57(1), 3242.

Esmaeili Aliabadi, D., \& Pourghannad, B. (2012). An improved approach to exchange non-rectangular departments in CRAFT algorithm. In 3rd International Conference on Industrial Engineering and Operations Management (IEOM 2012) (pp. 410-416). IEOM.

Green, J. C., Lee, J., \& Kozman, T. A. (2010). Managing lean manufacturing in material handling operations. International Journal of Production Research, 48(10), 2975-2993.

Hedau, V., \& Sharma, K. (2016). Improvement of plant layout using CRAFT. IJSART, 2(7), 38-43.
Kartika, I. M. (2014). Perancangan Tata Letak Area Produksi dengan Menggunakan Metode ARC pada CV Gading Putih Di Semarang. CAL YPTRA, 3(1), 1-18.

Lekan, O. K., Kayode, O. I., \& Abdulrazaq Morenikeji, A. (2017). Analysis of Plant Layout Design for Operational Efficiency With Craft Algorithms. Acta Universitatis Danubius. CEconomica, 13(4), 15-27.

Leung, M. T., Quintana, R., \& Chen, A.-S. (2008). A paradigm for Group Technology cellular layout planning in JIT facility. In 2008 IEEE International Conference on Industrial Engineering and Engineering Management (pp. 1174-1178). IEEE.

Mohamed, N., Rashid, M. F. F., Rose, A. N., \& Ting, W. Y. (2015). Production layout improvement for steel fabrication works. Journal of Industrial and Intelligent Information, 3(2), 133-137.

Pailin, D. B. (2013). Usulan Perbaikan Tata Letak Lantai Produksi Menggunakan Algoritma CRAFT dalam Meminimumkan Ongkos Material Handling dan Total Momen Jarak Perpindahan (Studi Kasus PT. Grand Kartect Jakarta). Jurnal Metris, 14(2), 73-82.

Prasad, N. H., Rajyalakshmi, G., \& Reddy, A. S. (2014). A typical manufacturing plant layout design using CRAFT algorithm. Procedia Engineering, 97, 1808-1814.

Ristyanadi, B., \& Orchidiawati, N. (2019). Perancangan Tata Letak di PT. Aerowisata Catering Service dengan Menggunakan Metode CRAFT (Computerized Relative Allocation Of Facilities Techniques). Media Mahardhika, 17(3), 394-399.

Sembiring, A. C., Tampubolon, J., Sitepu, G. A., Budiman, I., Tarigan, U. P. P., \& Tarigan, S. W. (2019). Redesigning the layout with algorithm craft on boiler manufacturing. In Journal of Physics: Conference Series (Vol. 1230, p. 12058). IOP Publishing.

Stephens, M. P., \& Meyers, F. E. (2013). Manufacturing facilities design and material handling. Purdue University Press.

Sujono, S., \& Lashkari, R. S. (2007). A multi- 
objective model of operation allocation and material handling system selection in FMS design. International Journal of Production Economics, 105(1), 116133.

VirendraPatil, M., \& Sagare, P. M. (2017). Case Study of Improvement Algorithm of Layout Design Using Craft Algorithm. International Journal of Engineering, Technology, Science and Research (IJETSR), 38-43.

White, J. A., Francis, R. L., Francis, R. L., \& McGinnis, L. F. (1992). Facility layout and location: An analytical approach. Prentice-Hall. 